\section{Multidisciplinary SCIENTIFIC JOURNAL OF MARITIME RESEARCH}

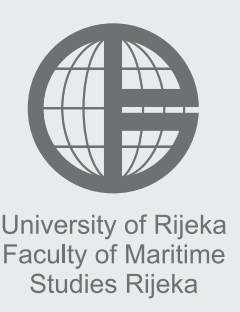

\author{
Multidisciplinarni \\ znanstveni časopis \\ POMORSTVO
}

\title{
Use of new information technologies in the maintenance of ship systems
}

\author{
Luka Mihanović ${ }^{1}$, Pančo Ristov ${ }^{2}$, Goran Belamarić ${ }^{2}$ \\ ${ }^{1}$ Ministry of Defence of the Republic of Croatia, Navy, Zrinsko-frankopanska b. b. Split, Croatia, e-mail: mlmihanovic@gmail.com \\ ${ }^{2}$ Faculty of Maritime Studies, Ruđera Boškovića 37, 21000 Split, Croatia
}

\begin{abstract}
In order to increase efficiency, security, reliability and availability of systems, while simultaneously reducing operational cost of maintenance, use of new information technologies continues to grow steadily. New information technologies are implemented as an integral part of ship systems or as an independent system, such as cloud computing, RFID (Radio Frequency Identification) technology, diagnostic technology, software agents, etc. New information technologies allow optimal use of computer (general purpose, dedicated or industrial) aided ship systems, which results in the reduction of crew sizes and more efficient maintenance of ship systems. Finally, they allow shipping companies and marine equipment manufacturers to offer more competitive prices together with ensured level of reliability and availability of ship systems.
\end{abstract}

\section{ARTICLE INFO}

Review article

Received 18 April 2016

Accepted 1 June 2016

\section{Key words:}

Diagnostic technology

Cloud computing

RFID technology

Ship

Ship systems

Shipping company

\section{Introduction}

Today's modern ships have many inbuilt systems supported by IT (information technology) resources that feature the latest advances in ship technology, such as propulsion system, navigation system and other systems on the command bridge, ship's cargo control and manipulation system, system of monitoring and management of fire and flooding protection system, electric power system, ship administration system, etc. The IT resources implemented in ship systems are increasingly taking on central functions in the creation, monitoring, control and implementing of maritime processes. Process modules, called control modules or controllers, are installed in ship systems. Their role is to monitor and control pre-defined operational parameters of the system they are installed in. Several dozens of autonomic process modules have been implemented on big ships, for example an ECU (Engine Control Unit) module controls and monitors running of the propulsion engine. For the sake of increased reliability and availability of the propulsion system, the process modules and data transfer buses are redundantly configured (Figure 1).

Most newbuilding vessels use standard racks with implemented computer resources (servers, personal computers, firewall, UPS - Uninterruptable Power Source,
Bridge Panel end Control Room Panel

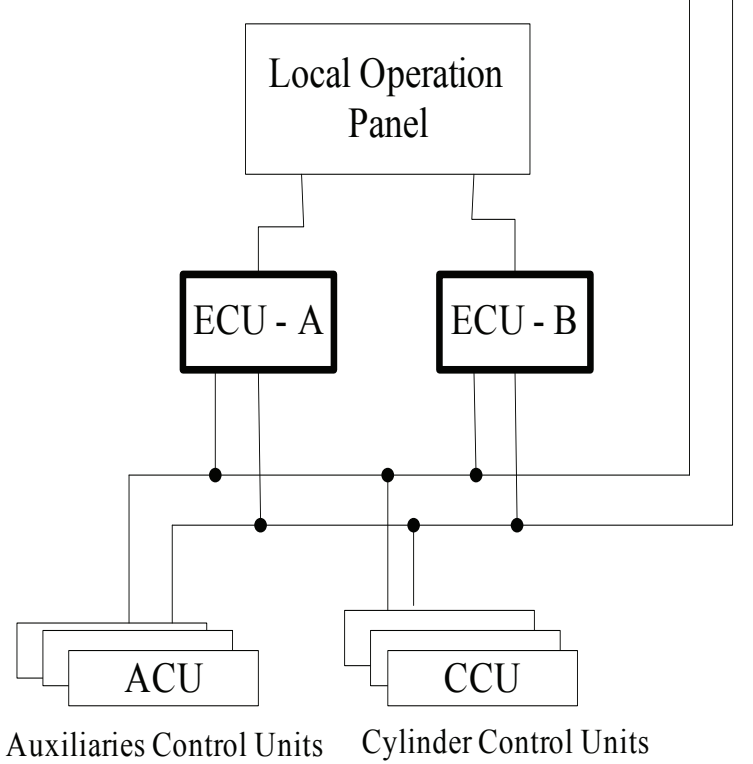

Figure 1 Redundant ECU and bus connection

Source: Authors 
industrial computers...) and network devices (patch panel, modem, switch, router...). Naval industry mostly uses single-piece 29U racks and/or three-piece 10U racks.

As a consequence, increasing implementation of IT resources in onboard ship systems brings up some new issues. One of them is how to keep ship systems or IT resources operational. This is one of main challenges not only for each shipping company, but also for every single ship. Absence of timely, properly executed, up-to-date and organized maintenance can directly cause difficulties in fulfilling the planned process. On the other hand, indirectly it can bring significant material and/or financial loss. Therefore, shipping companies demand reliable and secure operating of all ship systems, as well as efficient service support ensuring fast and safe delivery of spare parts to any harbour in the world. This is why the use of modern technologies presents a challenge to all employees of a shipping company, especially its technical department, as they are expected to deliver correct and non-stop operation, efficient monitoring, control and management of the naval fleet.

Wider bandwidth channels and cheaper satellite technologies allow new information technologies and thus the transfer of huge amounts of data via satellite, as well as online access to all databases and applications in computer clouds.

The project designers and manufacturers of sophisticated ship systems use modern IT, tools and procedures to a greater extent in order to increase reliability and availability of ship systems, and management of not only one ship, but a whole fleet of ships. New IT make the activity shorter and boost effectiveness of preventive and corrective maintenance, cut down costs of the system's life-cycle by quickly finding and delivering of spare parts, as well as by assisting ship crews to implement the activities of keeping the ship systems operational, simultaneously as ships sail the world seas and oceans.

The purpose of modern IT is to keep the projected reliability, availability, security and level of useful action with as low overall cost as possible (cost of maintenance + cost of non-operational time + cost of losses) for the shipping company.

\section{Diagnostic technology}

Naval science teaches us that reliability and availability of ship systems are the basic demands placed upon ship systems. Nowadays, meeting these demands can be eased by using techniques and methods of diagnostic technology.

The testing techniques can be hardware (comparison methodology and testing methodology) and software (response comparison methodology and self-diagnostic methodology).

Manufacturers of shipping equipment increasingly use the method of self-diagnostics in hardware and software modules of ship systems.

The primary purpose of diagnostic programs is prolonging operational time or shortening down time, as well as the ship system maintenance time. Diagnostic programs can be divided into several modules with different functions. The program modules may vary depending on the interface, test results, test types, functionality and display of results.

Modern diagnostic programs provide remote surveillance (checking module's operation and working order, detecting location, type, timing and cause of future defect, as well as continuous real-time comparison between module's fluid and suitable state) of a certain system. The surveillance is conducted starting with a preliminary announcement to the responsible ship crew member. Upon giving clearance to an authorized expert to make direct, remote contact with the targeted system, the expert can run system diagnostics, carry out the repair and finally provide expert advice to the crew about the repair technique. In other words, modern diagnostic programs give ship crews, shipping companies' representatives or authorized support service the insight into current status of ship systems via real-time monitoring of system parameters. The ability to establish a direct data communication regardless of the ship's position is a faster, more efficient, practical and far more cost-effective solution than sending an authorized service technician to a ship that could be in the middle of the ocean or barely reachable harbour. Modern satellite communications provide remote diagnostics, which can be run by a manufacturer, authorized support service or the shipping company expert (Figure 2).

The diagnostics system includes a group of programs for presenting and alerting correspondent diagnostic information to an operator or tech support person, so as to assume preventive measures prior to a defect. There are several types of diagnostic information, such as text and/or graph and/or sound alert, as in the case of RAID (Redundant Array of Independent Disks).

If the actual status based self-diagnostic programs are implemented in ship systems, information will be obtained about the system components' activities, operational data, impact data and running of the ship systems.

In case of discrepancy between the preset and actual parameters, diagnostic reports (alerts, warnings and notifications) are generated automatically, alerting the crew in time to take preventive measures before a malfunction or system failure takes place. For example, software will issue a warning for a pressure reaching maximum permitted value, unpermitted level of the propulsion engine vibration or fulfilling planned operation hours for regular maintenance of a device or ship system.

Naval industry is increasingly implementing self-diagnostic modules in hardware and software components of ship systems. Nearly all newbuilding ships can have multiple self-diagnostic modules developed on different platforms. All these surveillance programs generate corresponding diagnostic reports which are then respectively saved to storage media. New architectures are using server platforms, meaning that every system's diagnos- 


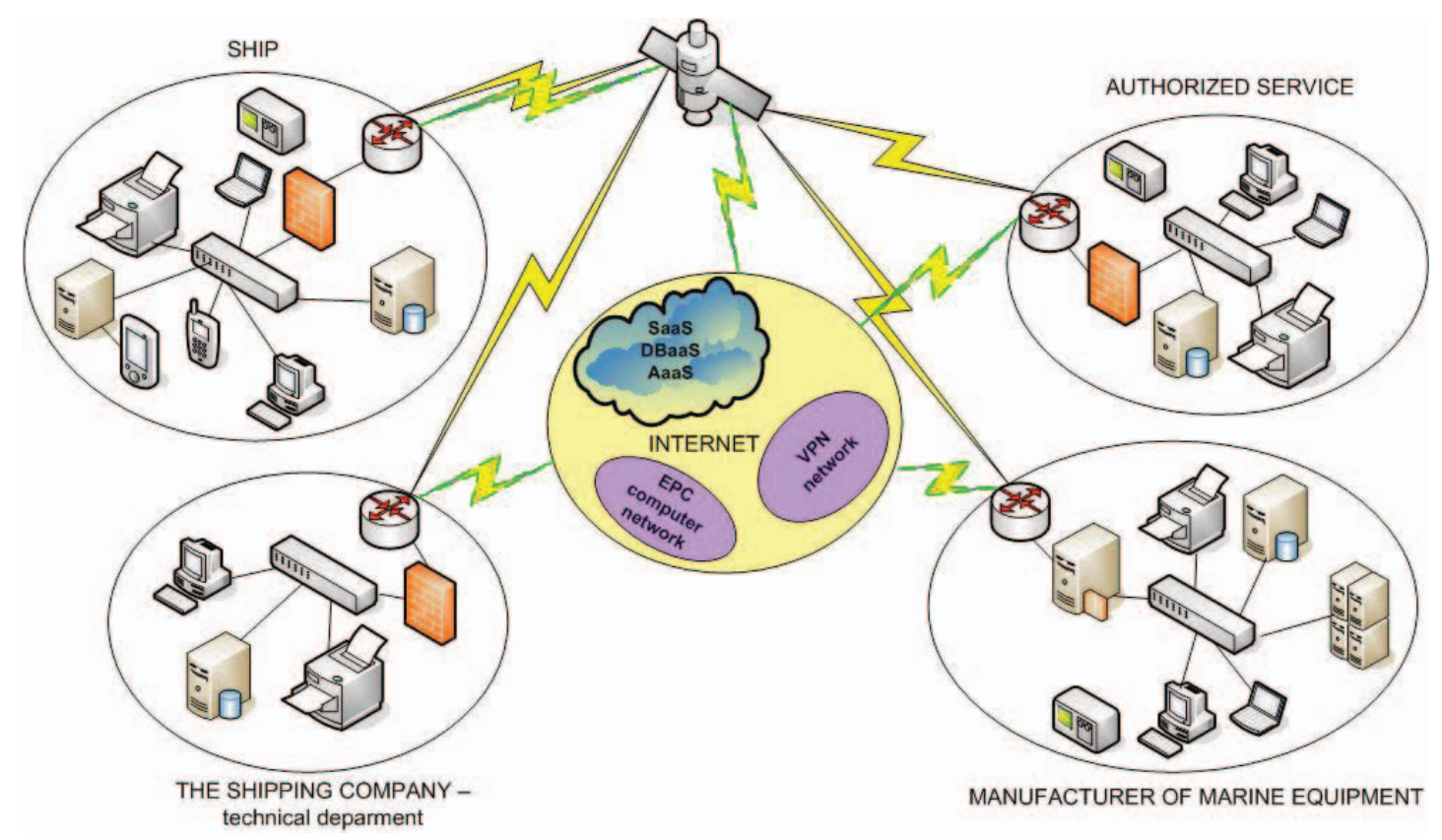

Figure 2 Global architecture of IT implementation

Source: Authors

tic report is saved through a corresponding interface to a dedicated server - alarm server. The alarm server is becoming an integral platform for storage and safekeeping of diagnostic reports offering the crew an integral overview of current situation from several onboard locations. Besides, the equipment manufacturer/authorized support service and/or shipping company's tech department have their own alarm server at disposal, which also receives and integrates diagnostic reports of all fleet ships in real time (Figure 2). That way the technical department can track all activities and compare data from all ships of the fleet, so head of the department can share "best practices" with the crews of ships whose performance is poorer than the rest. Real-time ship surveillance based on collecting real-time data, helps the shipping company's tech department to decide on potential prolongation of time period between certain activities, such as docking. Basic functions of the surveillance system are the following [1]:

- detection and error correction in system component operation

- tracking of hardware and software system module performances

- registration of activities on computer and other equipment

- tracking efficiency of hardware and software system modules

- detecting location, shape, timing and cause of future defects

- supporting a resource management module

- detecting security breaches and system's weak points
The simplest example of a diagnostic program for the computer system is the POST (Power On Self Test) sequence in starting the computer. Various IT equipment manufacturers offer more advanced diagnostic programs with a wider array of hardware and software diagnostics options of computer systems, such as: NORTON UTILITIES within Norton System Works tool [2], SANDRA (SiSoftware) [3] and AIDA64 Business Edition [4].

\subsection{Propulsion diagnostic systems}

High reliability, minimum maintenance cost and meeting growingly emphasised environmental demands in sea business, are all predominant demands for the operation of a ship as a whole, as well as all ship's systems. Ship's propulsion system is the basic subsystem of each ship, marine diesel engine is the central subsystem of the ship's propulsion system. It is functionally divided into several subsystems that make up a unique whole. Division of diesel engine to functional subsystems facilitates the experts' access to solving diagnostic problems.

Holistic approach to assessment of the condition of marine diesel engine consists of visual monitoring of the engine and its subsystems, monitoring operation parameters and testing gathered diagnostic data.

Assessment of the actual condition of the diesel engine leads to defining the process of engine maintenance based on the actual condition of the engine and its subsystems, thus significantly reducing unplanned stalls and preventing potential malfunctions of marine engines.

If the ship crew or personnel responsible for good working order of the shipping company's vessel and ship subsystems were to keep constant operational efficiency 
of the propulsion system by its maintenance, they would have to constantly monitor and register all the data available on the marine diesel engine, without stopping the engine. In attempt to achieve set goals, present-day diagnostic systems are focused on the control of ship's engine operations without obstructing normal work process. Such methodology includes the following: vibration analysis, noise emission, cooling emulsion analysis, exhaust gas analysis, ship engine lube oil analysis, endoscopy, analysis of heating process of running engine, etc.

Diagnostic programs implemented in the system of the ship's propulsion engine can display all physical measures that occur during the engine's operation, such as revolutions per minute, cooling emulsion temperature, engine oil pressure, intake air volume, turbine air pressure, current fuel consumption, etc. Apart from that, diagnostic programs can perform various interventions during the system's operation, such as activating and deactivating certain components, resetting service intervals and so on.

Applying new technological solutions in monitoring and measurement of marine diesel engine performance, as well as using computer engineering in diagnostics and repair on propulsion engines and all ship systems, help meeting a growing number of various criteria.

There is a vast array of all sorts of computer programs for operation monitoring, diagnostics and ship engine management, whereas the development of diagnostic system originates from two interdependent directions. Diagnostic systems are developed by IT industry components and ship automation and electronics manufacturers like Autronica, Norcontrol, ASEA, STL [5].

A Swedish-Swiss company ABB (Asea Brown Boveri) has developed RDS4Marine (Remote Diagnostics for Marine), a system that comprises several diagnostic subsystems - for example D4Propulsion (Diagnostics for Propulsion), D4Switchboard (Diagnostics for Switchboard), D4Azipod (Diagnostics for Azipod), etc. Using modern technologies, the ABB company has developed a RAP (Remote Access Platform) application and implemented it into the RDS4Marine system. RAP is a web-based application implemented in a server/client architecture. The application consists of RAP service centre and RAP diagnostics agent, which is installed in ABB shipping equipment. The RAP agent is directly linked with a server in the support service centre and it sends diagnostic reports [6].

Similarly, all relevant global manufacturers of diesel engines are developing independent diagnostic programs and expert systems for marine diesel engines' operation control and malfunction diagnostics. With increased reliability of propulsion system as a goal, expert systems are also employed, for example $\mathrm{CoCoS}$ (Computer Controlled Surveillance) - it consists of four software subsystems for engine control and surveillance, or MAPEX expert system by Wartsila (Sulcer) company, which is used for marine diesel engine maintenance and spare part management [7].
The implementation of diagnostic technology in marine diesel engine operation diagnostics has resulted in development of "intelligent" engines. The development of "intelligent" engines or propulsion systems results in decrease of ship crew, more reliable ship systems' operation, reduction of maintenance costs with an option of predicting malfunctions, condition based maintenance, and so on. Use of modern IT lets all participants and actions related to the ship and ship subsystems maintenance (human resources, preventive maintenance, corrective maintenance, condition based maintenance, spare part management...) achieve better efficiency and organisation, which are important prerequisites of safe sailing of the ship.

\section{Cloud computing}

Development of satellite technology supported by information technology has significantly reduced the cost of transfer of huge amounts of data, thus allowing shipping companies, manufacturers and authorized ship equipment services to use cloud computing utilities to a greater extent.

Cloud computing provides business entities to lease, not purchase, getting the exact information resources they want. The cost is reasonable, and hardware and software investments may even equal to none.

In cloud computing, programs, platform and infrastructure are sold to users as services, meaning that they are not sold as products.

A cloud can be used by a shipping company to store data, applications, functions and/or naval processes. Cloud computing provides an option where data and applications need not be stored in the same locations.

Cloud based business of a shipping company reduces the complexity of business processes which are related to its IT infrastructure, and provides security, availability and storage of data, back-up copies and upgrading all cloudrelated tasks [8].

Cloud computing is an information technology that provides three basic architecture models of service delivery, often called SPI (Software, Platform, Infrastructure) model, as in:

- Saas (Cloud Software as a Service) - it provides the user with available applications implemented in the cloud's infrastructure.

- IaaS (Cloud Infrastructure as a Service) - it provides the user with computer infrastructure.

- PaaS (Cloud Platform as a Service) - it provides the user with developing infrastructure, i.e. the user can develop their own applications, implement them in the cloud infrastructure and run the applications.

Regardless of the architecture of the delivery service model, there are four possible implementation models, each with good and bad sides: public cloud, private cloud, community cloud and hybrid cloud. The Right Scale Cloud Report showcases the cloud implementation models during 2015 and January 2016 (Table 1). 
Table 1 Representation models of implementation of cloud computing

\begin{tabular}{|c|c|c|c|}
\hline & Public cloud & Private cloud & Hybrid cloud \\
\hline 2015 & $88 \%$ & $63 \%$ & $58 \%$ \\
\hline $2016(9 \mathrm{Feb} 2016)$ & $89 \%$ & $77 \%$ & $71 \%$ \\
\hline
\end{tabular}

Source: Authors

The ongoing cloud computing development is leading to fast development of new models. What maritime industry finds interesting are the models that provide storage and analysis of data in the cloud, such as: DaaS (Data as a Service), DBaaS (Database as a Service), AaaS (Analysis as a Service) and the SaaS model.

Manufacturers and ship system suppliers increasingly use the DBaaS model. The DBaaS model provides an option to store various data for a certain type of device or system, or the data for a certain type of vessel. Specifically, databases store data and information containing technical blueprints, spare parts, technical and user instructions, and even copies of system and application program packages.

Very often computer clouds store elaborate solutions of past problems and methods how to handle potential problems for certain types of devices/systems.

The DBaaS model makes a centralized database and database management software located in the cloud. It means that the shipping company's office staff members have real-time access to information via a secure internet connection - anytime, anywhere (work from home, business trip, shipping agent). Using a suitable interface, ship's crew can access the ship's database which is as same as the cloud database. Regular data and information synchronisation ensures that the same updated data and information are used both by the crew onboard and office staff ashore. Managing one centralized cloud database is the foundation of efficient flow of information and transparent business in the shipping company. Basic characteristics of cloud databases should be the following: quick access, security and privacy, consistency, high availability, reliability, scalability and distributiveness.

The AaaS model analyses gathered data, such as fuel consumption of a single ship or all ships in the fleet, in order to test a hypothesis before interpreting incoming results. Only objective thinking, which is not based on subjective assumptions, can lead to true, actual results. The AaaS model helps the management in decisionmaking processes concerning the future of the shipping company.

In terms of business process analysis aboard ships and in the shipping company, the all-important and most acceptable cloud service model is the SaaS model. It encompasses all relevant business processes related to ship fleet technical management, meaning resource management, management, human resource management and reporting. Examples of SaaS models are MESPAS R5 $[10,11]$ and CMMS (Computerized Maintenance Management System) [12].

Japanese ClassNK (Marine and Industrial Service Department) uses for their propulsion system mainte- nance the SaaS, AaaS and DBaaS models. Employment of ClassNK CMAXS system brings more benefit to the shipping company, ship management company and ship crew. A wide array of benefits is visible in the following: reduced fixed costs of operation, sharing a wide range of information and data between all participants in the process, detailed overview of preventive and condition based maintenance procedures, real-time gathering data from ships, integration of all data from the fleet's ships, realtime analysis of gathered data, advising the crew on prevention of defects and repair of malfunctioning system, and access to fleet information from any location and at any time $[13,14,15]$.

Utilizing suitable cloud computing models, the shipping equipment manufacturers, shipping companies and other maritime institutions can achieve remarkable cost reduction on IT equipment, such as:

- costs of purchasing new computer resources

- costs of hardware and software maintenance or upgrade

- location for computer resources

- employment of very expensive IT technicians

- no database redundancy

- no slowdowns or bottlenecks in local area network

Implementation of SaaS model brings business transparency to the shipping company (real-time overview of technical, financial, material capacity, tool for fast and efficient data gathering for quality decision-making), effectiveness of process implementation (precise and clear directions, automatic synchronisation of all cloud applications in transfers of small amounts of data), integrated technical fleet management (program support covers all aspects of technical fleet management), provision management for ships and shipping company's offices, and transparent monitoring of general procurement process [8].

\section{Radio-frequency identification technology (RFID)}

Shipping equipment manufacturers are increasingly using RFID technology for tagging every component, including a device. RFID technology comprehends all systems that use radio-frequency waves for identification and tracking of objects or persons. In a narrower sense, RFID system implies a system consisting of an RFID reader, antenna, data interpreting system and RFID transponder (transmitter/ responder - tag) which carries information for identification and tracking of objects. Embedding RFID tags in ship device components and tagging devices provides numerous 
benefits and new, undreamed - of possibilities of more convenient and efficient conducting of activities in preventive and corrective ship system maintenance. The advantages brought by RFID technology, particularly safety and unique identification, are increasingly used in the process of spare part supply, as spare part availability is an important aspect of effective ship system servicing. Being the support to ships sailing all over the world, RFID technology is a quick and efficient tool for identifying a malfunctioning part and finding a needed spare anywhere in the world.

CMMS is a system dedicated to maintenance of systems and it delivers an efficient, safe and functional routine for maintenance management. The CMMS's are developed and implemented modularly for different maintenance strategies, various maintenance models, divers maintenance organizations and organizations activities. The CMMS system is server/client architecture based, and it is increasingly used as SaaS and DBaaS model in cloud computing. In order to boost safety, promptness, availability of new information flow in CMMS systems, their infrastructure is being implemented with RFID technology elements. Passive tags are predominantly used as data carriers. A tag can contain written/updated data about maintenance of certain elements or the whole system. Detailed information about the element or system can be obtained from EPC (Electronic Product Code) computer network.

Naval applications use passive tags with the following frequencies: $125 \mathrm{KHz}, 13.56 \mathrm{MHz}, 860-930 \mathrm{MHz}$, while some applications can also use active tags of 433 $\mathrm{MHz}$ or $2.45 \mathrm{GHz}$ frequencies. In usual practice, passive tags are prevailing due to lower price, longer life and no need for batteries. The CMMS system data and information can be accessed from any location and at any time. Implementation of RFID technology in CMMS systems brings two advantages. Firstly, one can see at any moment the exact status of inventory both inbuilt in ship systems and spares aboard the ship or in the company. Secondly,
RFID technology can prevent or reduce sources of error during data and information manipulation. The components of RFID technology allow automatic data input in the information system.

According to technical, scientific literature and practice, employment of RFID technology as an autonomous or integral part of maintenance processes results in the following benefits: improvement in performance of maintenance activities, cost decrease, reduction of maintenance activity cycles, lessening of risks in monitoring and control of ship property and equipment, enhanced safety and data/information accuracy, expansion of ship resource usage and increased revenue of the ship or shipping company.

Figure 3 showcases the architecture of EPC computer network. The EPC computer network is based on the internet infrastructure and provides use of new services for monitoring and tracking EPC objects.

The architecture of EPC computer network consists of three main subsystems: ONS (Object Naming Service) system, EPC-IS (EPC Information Services) system and EPC DS (EPC - Discovery Services) system. ONS system is a global system containing addresses where data is located about a product with an RFID tag in EPC - IS system. EPC - IS is a database created by a manufacturer, containing detailed description of each product (manufacturing date, product contents, deliveries, transport, etc.). EPC - DS is a database containing the whole history of EPC tag, which stores data about each change of product's status from its manufacture to sale.

The principle of EPC computer network's operation is similar to any other RFID system. A mobile RFID reader scans EPC data (serial number) of the item tagged with an RFID tag and then sends it to the EPC computer network. EPC data needs to be translated to URI (Uniform Resource Identifier), for example an IP address or URL (Uniform Resource Locator) that will allow access to the system containing the product's stored data. ONS system is simi-

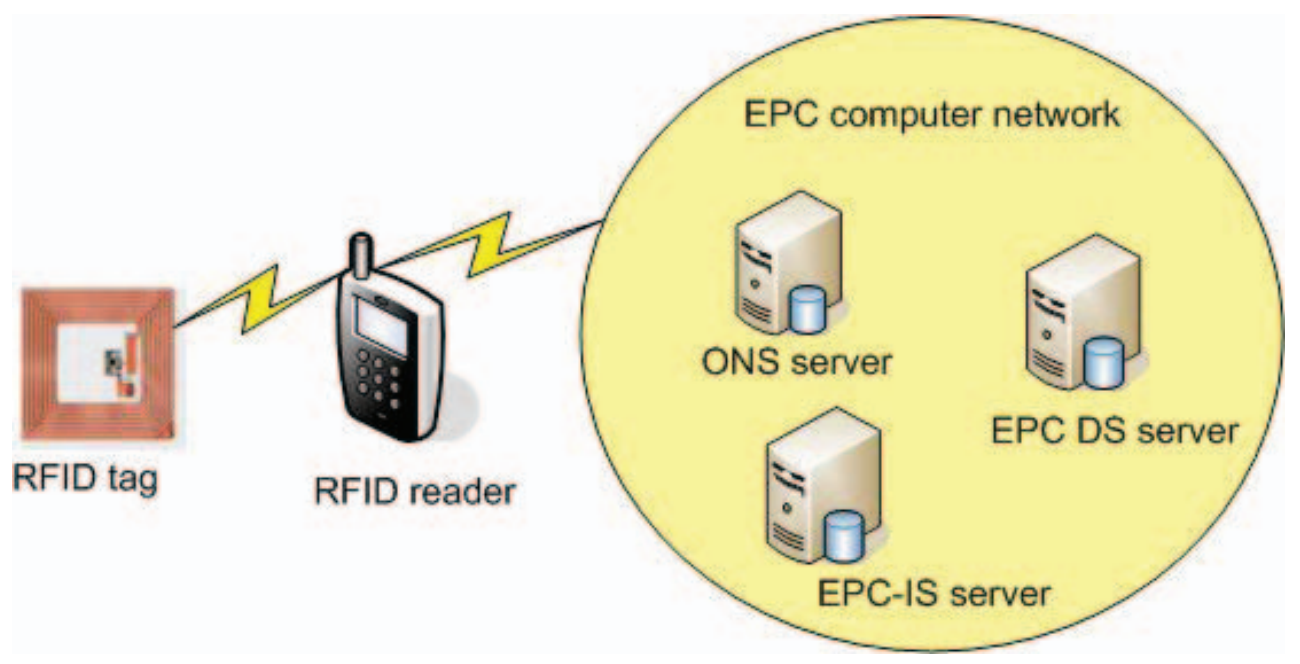

Figure 3 Global architecture of EPC computer network 
larly designed as DNS (Domain Name System) distributed database. In other words, ONS system provides information about URI, based on retrieved EPC item data. Using the right URI, it is possible to access EPC IS and obtain all needed information about the product.

EPC computer network is supported by VeriSign company. VeriSign is planning to introduce new services, including ONS system management, but they are also able to offer their services in a form of outsourcing to all interested companies that use RFID technology.

\section{Conclusion}

Possibilities of using new information technologies in the processes of management, monitoring and control of ship system maintenance are huge, which is highly visible in all newbuildings over the past few years. For that reason, naval industry constantly strives to perfect and adjust new technologies to ships' working conditions. New technologies can bring many advantages only if they operate without stopping, while ships sail successfully and make profit.

Maintenance of ship systems today and in the future cannot be imagined without the employment of modern methods and techniques of diagnostic technology and diagnostic equipment. Ship systems require sophisticated equipment for their maintenance. That is why for the development and design of ship systems naval industry increasingly implements and develops new methods and techniques in diagnostic processes, with an emphasis on self-diagnostics. This makes the process of ship system maintenance more convenient, where the overall quality of ship systems is improved together with increased satisfaction of seafarers and other participants in the complex ship maintenance process.

Cloud computing as a new IT introduces not only a vast array of new possibilities, but also challenges, starting from management to security of data, information, applications and infrastructure. The key to successful employment of services is in choosing the right cloud and performance of the chosen model for the shipping company or several shipping companies.

Before a shipping company opts for a service operator, they need to know if they can handle the risks of different architecture model's performances.
A huge benefit of RFID technology is that just one single reading, simultaneously employing the right anti-collision procedures, can read several different tags, which significantly saves time. This feature makes RFID technology most convenient for the process of control and tracking ship system elements, especially in the process of spare part supply during preventive/corrective maintenance.

\section{References}

[1] Ristov, P. Mrvica, A.: Pomorski integrirani informacijski sustavi ("Naval Integrated Information Systems"), Pomorski fakultet Split (Naval College of Split), 2013.

[2] https://us.norton.com/norton-utilities (20. 3. 2016.).

[3] http://www.softpedia.com/get/System/System-Info/SiSoftware-Sandra.shtml (20. 2. 2016.).

[4] http://www.aida64.com/products/aida64-business (20. 2. 2016.).

[5] Krakowski, R.: Diagnosis modern systems of marine diesel engine, Journal of KONES Powertrain and Transport, Vol. 21, No. 3, 2014.

[6] Nowak, J., Ådnanes, A.K.: Remote diagnostic services always on board, https://library.e.abb.com (30. 3. 2016).

[7] Radica, G.: Ekspertni sustavi za dijagnostiku stanja brodskih dizelskih motora (Expert Systems for diagnostics of marine diesel engine condition), Pomorski fakultet Split.

[8] Ristov, P., Perić, M., Tomas V.: The implementation of cloud computing in shipping companies, Scientific Journal of Maritime Research, 2014, Rijeka.

[9] http://www.rightscale.com/blog/cloud-industry-insights/cloud-computing-trends-2016-state-cloud-survey (20.3. 2016.).

[10] MESPAS AG Mespas, System requirements, Technical Management Software, Switzerland.

[11] MESPAS AG Mespas, The technical management software based on cloud computing, Technical Management Software, Switzerland.

[12] http://www.cloudcmms.com/cmms-software/cloudcmms-benefits-and- advantages/\#more-98: (1. 4. 2016).

[13] http://www.classnkturkey.com/Daihatsu.pdf (1. 4. 2016).

[14] http://www.classnk.com/hp/en/ (1. 4. 2016).

[15] http://classnkcs.co.jp/en/cmaxs/pdf/classnk_cmaxs_4el. pdf (15. 4. 2016).

[16] http://www.verisign.com/stellent/groups/public/documents/white_paper/002109.pdf (15. 4. 2016). 